\title{
An attempt at generating haploid lines of Poplar species for genetic manipulation and breeding programs
}

\author{
K.E. Wolter and B.H. McCown \\ Department of Horticulture, University of Wisconsin, Madison, WI 537'06, U.S.A.
}

\section{Introduction}

The successful establishment of haploidderived strains in herbaceous crop plants has proven that this procedure is both viable and extremely desirable. For example, over 80 new rice varieties have been established via this procedure (Siva Reddy et al., 1985) and 20000 ha of new tobacco varieties have been planted ( $\mathrm{Hu}$ et al., 1978). Production and use of haploids for tree breeding and biotechnological manipulation can be equally productive, yet only a relatively few attempts have been made to establish these lines (Wang et al., 1975; Chen et al., 1979; Zhu et al., 1980; Karnosky et al., 1981; Ho and Raj 1985; Hyun et al., 1986; and, for oak and horsechestnut, Jorgensen, personal communication). The use of haploids has special significance for genetic improvement in forest trees and other woody species where traditional breeding procedures and genetic manipulation are more difficult owing to: 1) long generation times typical of many tree species; 2) high heterozygosity; 3 ) factors, such as parthenocarpy and self incompatibility, which are common; and 4) poor embryo viability which often occurs. The main objective is, therefore, to establish haploid cell lines of selected
Poplar clones from anthers which will then be regenerated into shoots and roots for further manipulation via microculture procedures. Additional use of these tissues in protoplast fusion work will enable construction of new forest trees.

\section{Materials and Methods}

Poplar species were chosen as a model for the following reasons: 1) an extensive record of clonal lines exists with growth patterns and characteristics known for such genotypes; 2) availability of these clones as mature breeding stock; 3) some knowledge of poplar chromosome morphology; 4) viable procedures for poplar organogenesis and regeneration (Wolter, 1968; Russel and McCown, 1988); 5) transcription of desirable genes into poplar and increased recovery of transformed poplar shoots (Fillatti et al., 1987).

Attempts to obtain haploid tissues were made from the following clones: 1) Eugenei (NC 5326, $P$. deltoides $\times P$. nigra); 2) Androscoggin (NC11390, $P$. maximowiczii $\times$ P. trichocarpa); 3) Crandon (NC 5339) $P$. alba $\times P$. grandidentata; 4) Wisconsin wild selection (Wis. W-5). Catkins isolated during dormancy were stored at $-18^{\circ} \mathrm{C}$ (for a maximum of $3 \mathrm{mo}$ ), sterilized and allowed to elongate under ambient conditions. The scheme of Bajaj (1983) was followed with attempts at both pollen and anther cultures. Isolates were placed on different 
Table I.

\begin{tabular}{ll}
\hline Breeding & Biotechnology \\
\hline a. Recessive alleles expressed in one generation & a. Somacional hybridization \\
b. Homozygous diploids in one generation & b. Establish gene maps \\
c. Reduction of polyploid species & c. Somatic hybrids through fusion \\
$\begin{array}{ll}\text { d. Acceleration of superior homozygous lines } & \text { d.Paternal cytoplasmic inheritance } \\
\text { for self pollination and crosses } & \text { e.Detect haploid-associated metabolic pathways }\end{array}$
\end{tabular}

media (Wolter and Skoog, 1966; Lloyd and McCown, 1980) to initiate viable cultures as well as differentiation medium (Russel and McCown, 1986). Ploidy levels were monitored microscopically using a modified 8-hydroxyquinone/acetocarmine procedure of Somego (1978).

\section{Results}

Successful viable isolates were established for all tested Poplar clones from anther microspores on the 2,4-D (2,4-dichlorophenoxy-acetic acid; $0.04 \mathrm{mg} / \mathrm{l}$ ) medium of Wolter and Skoog (1966). Root differentiation was rapidly established for Eugenei with NAA (naphthalene acetic acid; $2 \mathrm{mg} / \mathrm{l}$ ); shoot organogenesis was not achieved with this clone, though numerous levels of cytokinins were tested. The Crandon isolates were viable and callus cultures were established, but organ differentiation was not obtained. Wisconsin W-5 was the most amenable for the production of shoots on a medium supplemented with $0.01 \mu \mathrm{M} N$-phenyl- $N$-1,2,3thiadiazol-5-ylurea (thiodiazuron). In all cases of successful shoot differentiation, ploidy levels were diploid. To date, differentiated roots have not been analyzed. Analysis of ploidy levels has been the largest technical problem of the investigation. Poplar species have the smallest amount of DNA of most tree species (7 pg/cell) thereby making monitoring extremely difficult.

\section{Discussion and Conclusion}

The conclusions from the results obtained to date are that production and maintenance of haploid tissue lines requires constant monitoring for ploidy levels. A rapid establishment of stable cultures (preferably shoot microculture) so as to avoid increasing ploidy levels through unstable callus subcultures is essential. If these objectives are maintained and haploid material is stabilized, the manipulations enumerated in Table 1 are possible (Bonga et al., 1987).

\section{References}

Bajaj Y.P.S. (1983) In vitro production of haploids. In: Handbook of Plant Cell Culture. Vol. I. (Evans D.A., Sharp W.R., Ammirato P.V. \& Yamada Y., eds.), MacMillan, New York, pp. 228-287

Bonga J.M., Von Aderkas P. \& James D. (1988) Potential application of haploid cultures of tree species. In: Genetic Manipulation of Woody Plants. (Hanover J.W. \& Keathley D.E., eds.), Plenum Press, New York, pp. 57-58

Chen Z., Chen F., Qian C., Wang C., Zhang S., Xu X., Ou X., He Y. \& Lu Z. (1979) A process of obtaining pollen grain plants from Hevea brasiliensis Muell. Arg. Sci. Sin. 22, 81-90

Fillatti J.J., Sellmer J.C., McCown B.H., Hassig B. \& Comai L. (1987) Agrobacterium-mediated transformation and regeneration of Poplar. Mol. Gen. Genet. 206, 192-199

Ho R.H. \& Raj Y. (1985) Haploid plant production through anther culture in Poplar. For. Ecol. Manage. 13, 133-142 
Hu H., Hsi T.Y., Tseng C.C., Ouyang T.W. \& Ching C.K. (1978) Application of anther cultures to crop plants. In: Frontiers of Plant Tissue Culture. (Thorpe T.A., ed.), Proc. 4th International Assoc. of Plant Tissue Culture. Univ. of Calgary, Canada. pp. 123-130

Hyun S.K., Kim J.H., Noh E.W. \& Park J.I. (1986) Induction of haploid plants of Populus species. In: Plant Tissue Culture and its Applications. (Withus L.A. \& Alderson P.G., eds.), Butterworth, London, pp. 413-416

Karnosky D.F. (1981) Potential for forest tree improvement via tissue culture. Bioscience 31 , 114-119

Lloyd G. \& McCown B.H. (1980) Commerciallyfeasible micropropagation of mountain laurel, Kalmia latifolia, by use of tip shoot cultures. In: Proc. Int. Plant Propagators Soc. 30, 421-427

Russell J.E. \& McCown B.H. (1986) Culture and regeneration of Populus leaf protoplasts isolated from non-seedling tissue. Plant Sci. 46, 133-142
Russell J.E. \& McCown B.H. (1988) Recovery of plants from leaf protoplasts of hybrid poplar and aspen clones. Plant Sci. Rep. 7, 59-62

Siva Reddy V., Leelavathi S. \& Sen S.K. (1985) Influence of genotype and culture medium on microspore callus induction and green plant regeneration in anthers of Oryza sativa. Physiol. Plant. 63, 309-314

Somego M. (1978) Cytogenetical studies of the Dipterocarpaceav. Malay. For. 41, 358-365

Wang C.C., Chu Z.C. \& Sun C.S. (1975) The induction of poplar pollen plants. Acta Bot. Sin. $17,56-59$

Wolter K.E. (1968) Root and shoot initiation in aspen callus cultures. Nature 219, 509-510

Wolter K.E. \& Skoog F. (1966) Nutritional requirements of Fraxinus callus cultures. $A m . J$. Bot. 41, 272-280

Zhu X.X., Wang R.L. \& Liang Y.L. (1980) Induction of poplar pollen plantlets. Sci. Silvae Sin. $16,190-197$ 